\section{A novel index to evaluate ineffective erythropoiesis in hematological diseases offers insights into sickle cell disease}

Ineffective erythropoiesis (IE) is a significant pathological factor in many types of anemia including $\beta$-thalassemia and myelodysplasia and has more recently been described in sickle cell disease (SCD). We have evaluated a novel index of ineffective erythropoiesis (IoIE) as a way of quantitating IE and facilitating its comparison between patients, conditions, and the effects of treatments. We calculated IoIE by dividing the plasma concentration of soluble transferrin receptor (sTfR, nmol/L) (proportionate to the volume of erythroid tissue) by the absolute reticulocyte count (ARC, x10 $1 / \mathrm{L}$ ) (effective erythroid output from the bone marrow). The upper limit of normal IoIE was calculated at 0.28 , using the established normal ranges of sTfR and ARC, and confirmed using control samples. We studied 414 SCD patients and show that IE is a feature of patients with HbSS (median IoIE 0.37), but not HbSC (median IoIE 0.27). We validated IoIE as a measure of IE in a cohort of 44 patients with $\mathrm{HbE}$-beta thalassemia, a condition in which IE is known to play a major part and, as expected, found high levels (median IoIE 1.46). Within the HbSS cohort, we find higher $\mathrm{HbF}$ levels associate with reduced IE and that transfusion reduces IE, whereas hydroxyurea (HU) treatment appears to lead to increased IE. This index is a simple and meaningful measure of IE, showing that it is clinically important in SCD, and suggesting novel therapeutic approaches.

IE is the abnormal differentiation of erythroid progenitors, with an expanded progenitor compartment, increased erythroblast destruction and a relative paucity of reticulocytes produced compared to the volume of the erythron. ${ }^{1}$ IE is well described in beta-thalassemia but less so in SCD, where anemia is generally attributed to hemolysis. ${ }^{2}$ There is, however, evidence of dysfunctional erythroid differentiation in SCD. Erythroblasts isolated from the bone marrow of SCD patients sickle under hypoxic conditions ${ }^{3}$ whilst analysis of chimeric hematopoiesis in non-myeloablative transplanted SCD patients have demonstrated a survival advantage of the donor erythroid progenitor cells. ${ }^{4}$ More recently, high levels of apoptosis between the polychromatic and orthochromatic stages were identified, with fetal hemoglobin $(\mathrm{HbF})$ being a key protective factor against this. ${ }^{5}$

Quantitation of IE in patients would facilitate its study in SCD and other anemias and allow an assessment of novel treatments. Transferrin receptor (CD71) is a membrane protein expressed during erythropoiesis. It is also released into the circulation, with its serum concentration shown to be proportional to the mass of erythropoietic tissue. ${ }^{6,7}$ Soluble transferrin receptor (sTfR) levels are elevated in SCD, reflecting an increased erythropoietic drive, but show no correlation with disease severity. ${ }^{8} \mathrm{We}$ propose a meaningful representation of IE that can be determined by measuring the ratio of the mass of erythropoietic tissue (sTfR) to the erythroid output from the marrow (ARC), analogous to the way the reticulocyte percent correlates with the rate of hemolysis. ${ }^{9}$ Where IE is occurring, the erythron mass will be large, with higher sTfR levels, whilst the relative output of reticulocytes (ARC) will be lower, and the ratio will be higher. We refer to this ratio as the Index of Ineffective Erythropoiesis (IoIE), and explore its significance in patients with SCD.

Table 1. Biological parameters of controls, $\mathrm{SCD}$ and $\mathrm{HbE} / \beta$-thalassaemia patients.

\begin{tabular}{|c|c|c|c|c|c|c|c|c|}
\hline Genotype & AA & & SS & & SC & $S / \beta+$ & $\mathrm{HbE} / \beta-\mathrm{t}$ & alassemia \\
\hline Treatment & Control & Non- treated & Transfusion & $\mathrm{HC}$ & Non- treated & Non- treated & Non- treated & Transfusion \\
\hline Number of patients & 22 & 182 & 58 & 50 & 87 & 12 & 23 & 22 \\
\hline $\begin{array}{l}\text { Mean age in years } \\
\text { (min - max) }\end{array}$ & $\begin{array}{c}42.77 \\
(16-93)\end{array}$ & $\begin{array}{c}31.7 \\
(17.3-63.58)\end{array}$ & $\begin{array}{c}29.17 \\
(16.94-51.75)\end{array}$ & $\begin{array}{c}28.71 \\
(18.1-57.46)\end{array}$ & $\begin{array}{c}39.15 \\
(17.9-74.9)\end{array}$ & $\begin{array}{c}42.48 \\
(18.93-68.28)\end{array}$ & $\begin{array}{c}11 \\
(1-39)\end{array}$ & $\begin{array}{c}18.5 \\
(4-53)\end{array}$ \\
\hline Gender & $\begin{array}{l}8 \text { Female, } \\
14 \text { Male }\end{array}$ & $\begin{array}{l}110 \text { Female, } \\
72 \text { Male }\end{array}$ & $\begin{array}{l}26 \text { Female, } \\
32 \text { Male }\end{array}$ & $\begin{array}{l}28 \text { Female, } \\
22 \text { Male }\end{array}$ & $\begin{array}{l}59 \text { Female, } \\
28 \text { Male }\end{array}$ & $\begin{array}{l}8 \text { Female, } \\
4 \text { male }\end{array}$ & $\begin{array}{l}11 \text { Female, } \\
12 \text { Male }\end{array}$ & $\begin{array}{c}7 \text { Female, } \\
15 \text { Male }\end{array}$ \\
\hline $\mathrm{gHbF}$ & $\mathrm{N} / \mathrm{A}$ & $\begin{array}{c}2.718 \\
(1.89-2.62)\end{array}$ & $\begin{array}{c}2.135 \\
(1.89-2.69)\end{array}$ & $\begin{array}{c}2.137 \\
(1.89-2.49)\end{array}$ & $\begin{array}{c}2.1777 \\
(1.89-2.49)\end{array}$ & $\begin{array}{c}2.144 \\
(1.89-2.32)\end{array}$ & N/A & $\mathrm{N} / \mathrm{A}$ \\
\hline$\alpha$-thalassemic & $\mathrm{N} / \mathrm{A}$ & $\begin{array}{c}131 \alpha \alpha / \alpha \alpha \\
38 \alpha \alpha / \alpha^{-} \\
13 \alpha-/ \alpha^{-}\end{array}$ & $\begin{array}{c}39 \alpha \alpha / \alpha \alpha \\
17 \alpha \alpha / \alpha- \\
2 \alpha-/-\alpha\end{array}$ & $\begin{array}{c}31 \alpha \alpha / \alpha \alpha \\
15 \alpha \alpha / \alpha- \\
4 \alpha-/ \alpha^{-}\end{array}$ & $\begin{array}{c}62 \alpha \alpha / \alpha \alpha \\
23 \alpha \alpha / \alpha- \\
2 \alpha-/ \alpha\end{array}$ & $\begin{array}{c}8 \alpha \alpha / \alpha \alpha \\
3 \alpha \alpha /-\alpha \\
1 \alpha-/ \alpha-\end{array}$ & N/A & N/A \\
\hline Hemoglobin $(\mathrm{g} / \mathrm{dL})$ & $\mathrm{N} / \mathrm{A}$ & $\begin{array}{c}84.16 \\
(42-124.3)\end{array}$ & $\begin{array}{c}95.96 \\
(61.8-121)^{* * * *}\end{array}$ & $\begin{array}{c}88.44 \\
(41.6-113.8)^{*}\end{array}$ & $\begin{array}{c}115.4 \\
(80-147.5)\end{array}$ & 122.1 & $\begin{array}{c}71.57 \\
(10-105)\end{array}$ & $\begin{array}{c}94.5 \\
(11.9-132)^{* * *}\end{array}$ \\
\hline $\mathrm{HbF}(\%)$ & $\mathrm{N} / \mathrm{A}$ & $\begin{array}{c}6.8 \\
(0.2-25.6)\end{array}$ & $\begin{array}{c}3.03 \\
(0.2-11.1)^{* * * *}\end{array}$ & $\begin{array}{c}10.38 \\
(1.25-29.02)^{* * * *}\end{array}$ & $\begin{array}{c}1.836 \\
(0.2-11.1)\end{array}$ & $\begin{array}{c}5.3 \\
(0.7-11.6)\end{array}$ & $\begin{array}{c}45.36 \\
(8.9-66)\end{array}$ & 35 \\
\hline Erythropoietin & $\mathrm{N} / \mathrm{A}$ & $\begin{array}{c}104.8 \\
(10.6-800)\end{array}$ & $\begin{array}{c}59.45 \\
(21.3-187)^{* * * *}\end{array}$ & $\begin{array}{c}112.3 \\
(24.3-354.3)\end{array}$ & $\begin{array}{c}41.34 \\
(14-143)\end{array}$ & $\begin{array}{c}29.84 \\
(9.6-81.15)\end{array}$ & $\mathrm{N} / \mathrm{A}$ & N/A \\
\hline
\end{tabular}




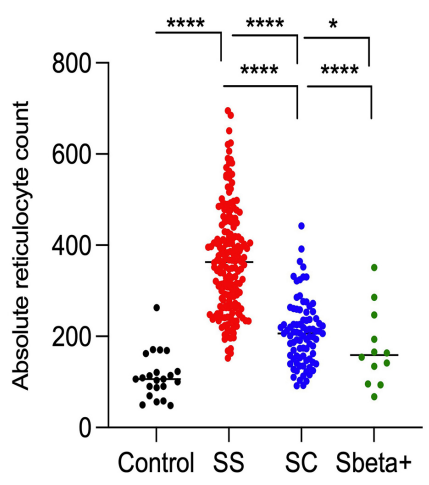

D

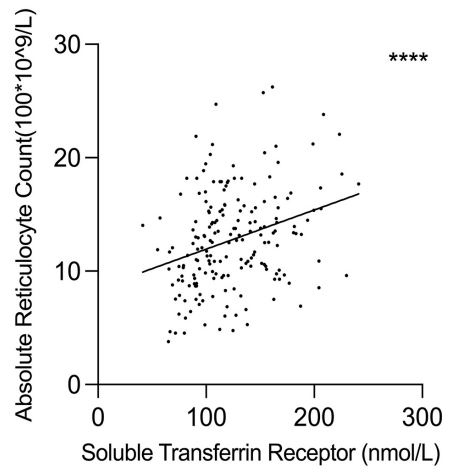

G

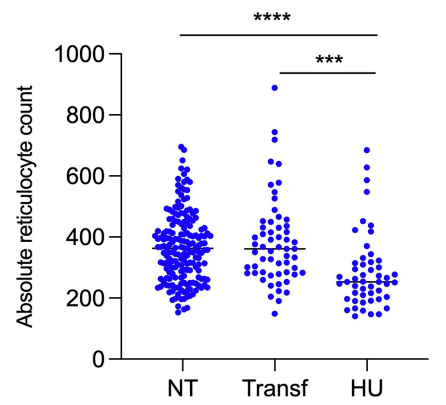

J

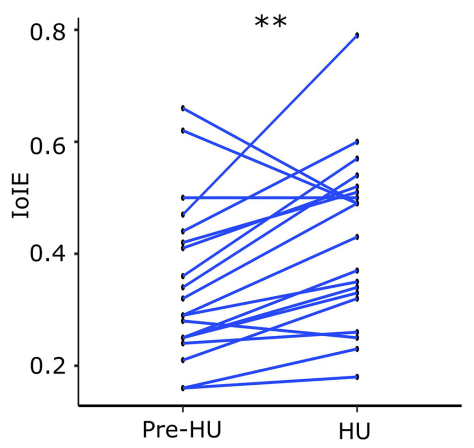

B

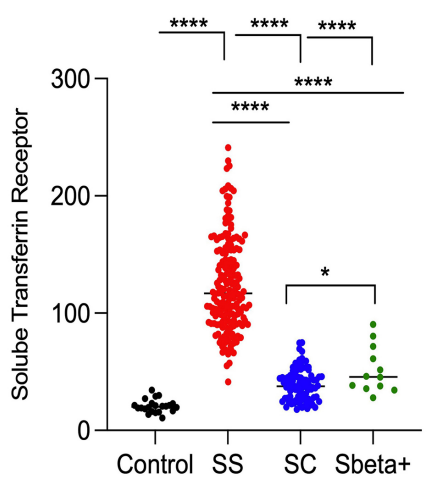

E

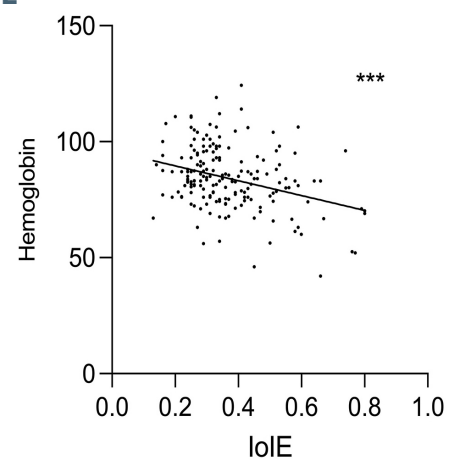

H

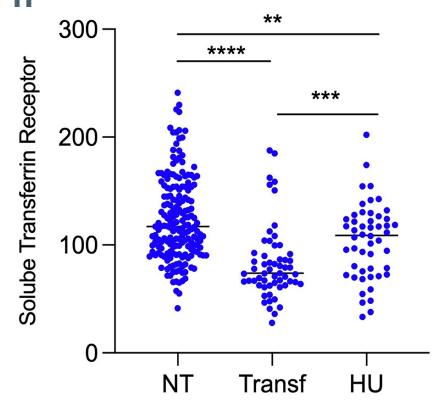

K

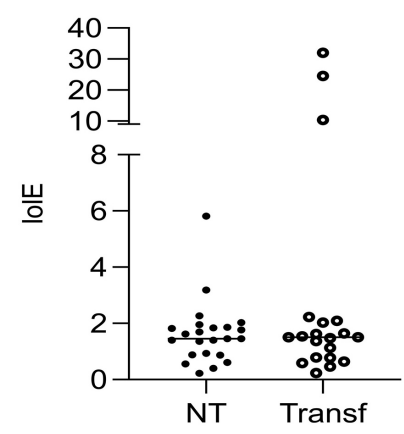

C

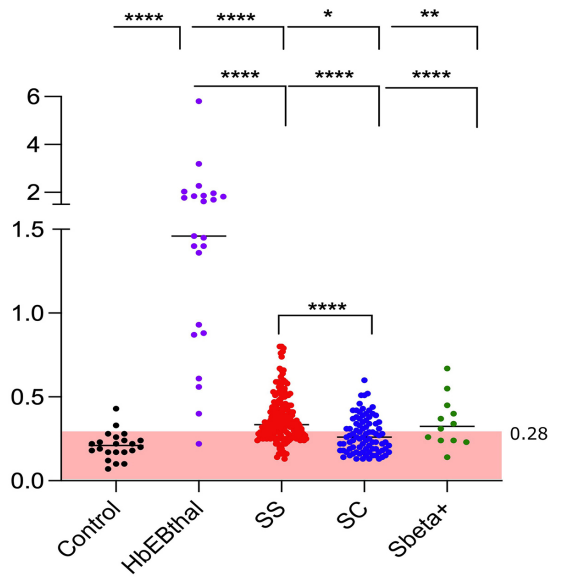

F

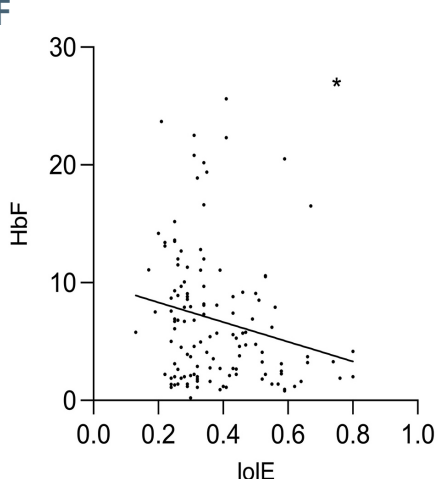

I

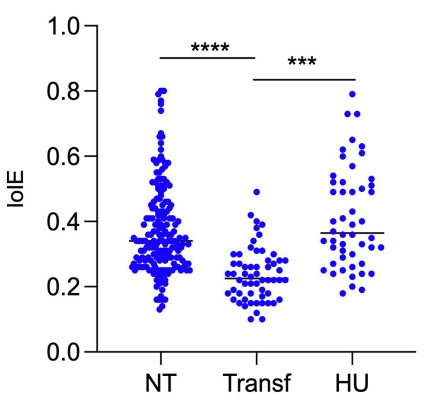

L

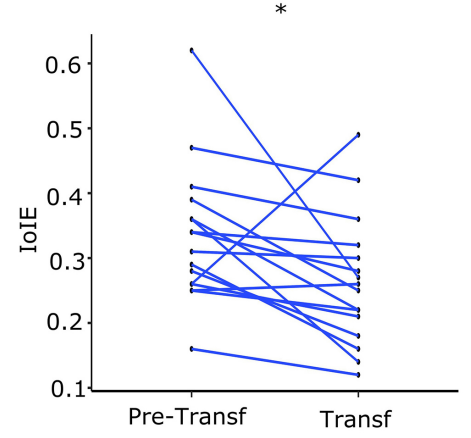

Figure 1. Index of ineffective erythropoeisis and other biological parameters in SCD. A graph representing the (A) absolute reticulocyte count (ARC) (B) Soluble Transferrin Receptor (sTfr) and (C) Index of Ineffective Erythropoiesis (IolE) in control $(n=22), \mathrm{HbSS}(n=182), \mathrm{HbSC}(n=87)$ and HbS/ $\beta^{+}(n=12)$ patients; the red box represents the normal range of lolE. A Spearman correlation plot between (D) ARC and sTfr, (E) Hemoglobin and loIE and (F) Fetal hemoglobin and lolE in the HbSS group ( $n=182)$. A graph showing the (G) ARC, $(H)$ sTfR and (I) lolE in non-treated $(n=182)$, transfusion $(n=58)$ and HU $(n=50) H b S S$ groups. $* P<0.05$, $* * P<0.01, * * * P<0.001 * * * * P<0.0001$. (J) Effect of HU therapy on patient IolE measurements. Each line represents the change in lolE of an individual patient from before to during HU therapy $(n=20)$. (K) loIE in non-treated $(n=23)$ and transfused $(n=22) H b E / \beta$-thalassemia patients $(L)$ Effect of transfusion therapy on patient lolE measurements $(n=17)$. 
We also validate this index in a cohort of patients with non-transfusion dependent $\mathrm{HbE} / \beta$-thalassemia, in which IE is known to predominate and in a control group with no iron deficiency, no hematological disease or other condition which might impact erythropoiesis.

All patients with SCD were recruited from King's College Hospital, London, UK. Written informed consent was obtained through three approved study protocols (LREC 01-083, 07/H0606/165, and 12/LO/1610). Patient electronic records were reviewed from 2008 to the present for all measurements of sTfR and ARC taken on the same day in the outpatient setting. Contemporaneous Hemoglobin $(\mathrm{Hb})$ and $\mathrm{HbF}$ levels were also recorded and a note made of disease modifying therapy: ongoing regular blood transfusion within 90 days, HU use, or neither. Measurements were excluded if there was evidence of iron deficiency (serum ferritin $<30$ micrograms/L), or if the patient was younger than 16 years of age at time of sampling. ${ }^{10}$ Data from a previous study of patients with $\mathrm{HbE} / \beta$ thalassaemia ${ }^{11}$ were collected and analyzed to validate the index. Data from 22 control samples was also analyzed; these were samples from adult patients taken for clinical reasons. They were without iron deficiency or any other condition known to affect erythropoiesis or red cell survival.

Determination of $\alpha$ thalassemia, G6PD and $\mathrm{g}(\mathrm{HbF})$, a composite measure of the major genetic determinants of $\mathrm{HbF}$, in this cohort are described elsewhere. ${ }^{12}$ sTfR was measured using an ELISA (R\&D Systems, Minneapolis, USA) and reticulocytes were measured using automated counting based on RNA staining (Siemens Healthcare, Erlangen, Germany).

Index of ineffective erythropoiesis (IoIE) was calculated by dividing sTfR $(\mathrm{nmol} / \mathrm{L})$ by the ARC $\left(\mathrm{x} 10^{9} / \mathrm{L}\right)$. We defined the limit of the normal range by applying this formula to the well-established upper limit of the normal ranges of $\operatorname{sTfR}(28.1 \mathrm{nmol} / \mathrm{L})$ and ARC $\left(100 \times 10^{9} / \mathrm{L}\right)$, giving a value of 0.28 . We validated this with control samples. Where multiple measurements were available, averages were taken. Statistical analyses were performed with GraphPad Prism (version 9). The data were analyzed using the Mann-Whitney unpaired test and the Wilcoxon paired test, as indicated. Correlations were performed using the Spearman correlation.

There were 22 controls, 182 patients with $\mathrm{HbSS}, 87$ with $\mathrm{HbSC}$ and 12 with $\mathrm{HbS} / \beta$-thalassemia ${ }^{+}$without disease modifying therapy, with a comparable age range and sex ratio (Table 1). As expected, HbSS patients had significantly lower $\mathrm{Hb}$ levels and higher ARC, compared to patients with either $\mathrm{HbSC}$ or $\mathrm{HbS} / \beta^{+}$-thalassemia (Figure $1 \mathrm{~A})$, and sTfR levels are significantly higher in the HbSS genotype (Figure 1B). There was a strong correlation between ARC and sTfR levels $(r=0.3773, P<0.0001$, Figure 1D).

The IoIE in the non-treated HbSS group was elevated, at 0.37 , compared to the control group (0.209), suggesting some degree of IE. This was significantly less than in the validation cohort of 23 non-transfused patients with $\mathrm{HbE} / \beta$-thalassemia, with a median IoIE of 1.46 (Table 1 , Figure $1 \mathrm{C}$ ). By contrast, in the HbSC group, the IoIE (0.27) was in the normal range though it was slightly higher than in the control group $(P=0.0174)$. The difference between the HbSS and HbSC groups was statistically significant $(P<0.0001)$. Although the numbers were small, the IoIE in the $\mathrm{HbS} / \beta^{+}$-thalassemia group was higher (0.35) than that of HbSC and significantly higher than the control $(P=0.0015)$, despite similar levels of anemia and disease severity compared to HbSC (Figure 1C).

We assessed factors known to influence disease sever- ity in $\mathrm{HbSS}$ with the IoIE. We found a significant negative correlation with $\mathrm{Hb}\left(\mathrm{r}=-0.32, P=6 \times 10^{-6}\right)$, (Figure 1E), and $\mathrm{HbF}(\mathrm{r}=-0.20, P=0.02)$ (Figure $1 \mathrm{~F})$, but no association with G6PD status, $(P=0.062)$, deletional $\alpha$-thalassemia $(P=0.26)$, or $\mathrm{g}(\mathrm{HbF})(\mathrm{r}=0.02, P=0.82)$. These findings, together with previous work implicating $\mathrm{HbF}$ levels in $\mathrm{IE},{ }^{5}$ may suggest that increased $\gamma$ globin synthesis in erythroblasts reduces IE in SCD and contributes to higher $\mathrm{Hb}$ levels by improving erythropoiesis, as well as prolonging red cell survival.

$\mathrm{HU}$ and blood transfusion therapy are the two main treatment options in patients with SCD. We evaluated the IoIE in 58 regularly transfused and 50 HU-treated patients. The transfused patients were on long-term regular transfusions, mostly because of cerebrovascular disease to keep the HbS level below $30 \%$. The patients on $\mathrm{HU}$ had all been taking it for at least six months and were treated according to clinical response rather than at maximum tolerated dose. In each of these groups, the measurements of $\mathrm{Hb}, \mathrm{HbF}$, and ARC differed from baseline in accordance with previously published data (Table 1), ${ }^{13,14}$ whilst sTfR levels decreased in both groups (Figure $1 \mathrm{H}$ ). By contrast, the IoIE was significantly lower with transfusions (IoIE $=0.26, P=7.2 \times 10^{-6}$ ), but significantly higher with HU treatment ( $\mathrm{IoIE}=0.42, P=0.042$ ) (Figure $1 \mathrm{I})$. We validated these findings in 17 patients for whom both baseline and post-transfusion measurements were available (paired $t$-test, $P=0.019$ ) (Figure $1 \mathrm{~L}$ ) and 20 patients for whom both baseline and HU treated measurements were available (paired $t$-test, $P=0.004$ ) and confirmed that IoIE actively increased with $\mathrm{HU}$ (Figure 1J) and decreased with transfusion (Figure $1 \mathrm{~K}$ ). There was no correlation between $\mathrm{HbF}$ and IoIE in patients on $\mathrm{HU}(P=0.072)$, although numbers were small.

The improvement in IoIE seen in patients on blood transfusions contrasts to that seen with regular blood transfusions to treat $\mathrm{HbE} / \beta$-thalassemia ( $\mathrm{n}=21)$, where IoIE remained high at 1.51 (Figure $1 \mathrm{~K}$ ). We suggest this reflects the inherent difference in the causes of IE in thalassemia compared to $\mathrm{HbSS}$. In thalassemia there is intrinsic IE due to the imbalance in globin chain synthesis, which will not be significantly altered by blood transfusion whereas the IE seen in $\mathrm{HbSS}$ may be, in part, extrinsically induced by the dysfunctional bone marrow microenvironment, one shown to improve with recurrent blood transfusion in a recent study of a mouse model. ${ }^{15}$

The relationship between $\mathrm{HbF}$ levels and IE in SCD is complex, as demonstrated by the different effects of naturally occurring high $\mathrm{HbF}$ levels (reduced IE) and $\mathrm{HU}$ (increased IE). This suggests two opposing mechanisms: inherited high $\mathrm{HbF}$ levels reduce erythrocyte $\mathrm{HbS}$ concentrations and so reduce intramedullary $\mathrm{HbS}$ polymerization with improved erythroid survival; conversely, high levels of IE lead to increased selective advantage in favor of cells expressing more $\mathrm{HbF}^{16}$ resulting in higher circulating $\mathrm{HbF}$ levels; this may be one mechanism through which $\mathrm{HU}$ mediates its therapeutic increase in $\mathrm{HbF}$, and explains why there is a relative weak correlation between $\mathrm{HbF}$ and ineffective erythropoiesis.

In summary, we propose the IoIE as a simple, meaningful and useful measure of ineffective erythropoiesis. We use it to demonstrate that IE exists in patients with $\mathrm{HbSS}$, but not $\mathrm{HbSC}$, and that the genetic ability to synthesize more $\mathrm{HbF}$ is associated with less IE. Furthermore, we make the clinically important observation that HU increases IE whilst blood transfusion reduces IE. Further investigations are required to understand this action of $\mathrm{HU}$ in increasing IE in SCD. ${ }^{17} \mathrm{HU}$ has a direct effect on 
cell division which would be expected to increase IE. However, it may also be acting in other ways, such as increasing stress erythropoiesis in the bone marrow niche of SCD patients. IoIE may be useful to monitor the effects of transfusion and HU in SCD, and to evaluate the effects of novel therapies.

\section{John Brewin, ${ }^{1,2^{*}}$ Sara El Hoss, ${ }^{1 *}$ John Strouboulis ${ }^{1}$ and David Rees ${ }^{1,2}$}

${ }^{1}$ Molecular Haematology, Comprehensive Cancer Centre, School of Cancer and Pharmaceutical Sciences, King's College London and ${ }^{2}$ Department of Haematological Medicine, King's College Hospital, London, UK

* JB and SEH contributed equally as co-first authors.

Correspondence:

SARAELHOSS - sara.el_hoss@kcl.ac.uk

doi:10.3324/haematol.2021.279623

Received: July 12, 2021.

Accepted: October 11, 2021.

Pre-published: October 21, 2021.

Disclosures: no conflicts of interest to disclose.

Contributions: JB collected data, analysed, wrote and edited the manuscript; SEH analysed data, wrote and edited the manuscript; $J S$ contributed to the design of the study, interpretation of data and wrote and edited the manuscript; DR designed the study, wrote and edited the manuscript.

Acknowledgments: we would like to thank the patients involved in this study and the medical staff of $\mathrm{KCH}$ for taking care of the patients. We also thank the members of the Molecular Haematology research lab at King's College London for their support during this work.

\section{References}

1. Orkin SH. Diversification of haematopoietic stem cells to specific lineages. Nat Rev Genet. 2000:1(1):57-64.

2. Ribeil JA, Arlet JB, Dussiot M, et al. Ineffective erythropoiesis in beta-thalassemia. ScientificWorldJournal. 2013;2013:394295.

3. Hasegawa S, Rodgers GP, Dwyer N, et al. Sickling of nucleated ery- throid precursors from patients with sickle cell anemia. Exp Hematol. 1998;26(4):314-319.

4. Wu CJ, Krishnamurti L, Kutok JL, et al. Evidence for ineffective erythropoiesis in severe sickle cell disease. Blood. 2005;106(10):36393645.

5. El Hoss S, Cochet S, Godard A, et al. Fetal hemoglobin rescues ineffective erythropoiesis in sickle cell disease. Haematologica. 2021; 106(10):2707-2719

6. Huebers HA, Beguin Y, Pootrakul P, Einspahr D, Finch CA. Intact transferrin receptors in human plasma and their relation to erythropoiesis. Blood. 1990;75(1):102-107.

7. Lulla RR, Thompson AA, Liem RI. Elevated soluble transferrin receptor levels reflect increased erythropoietic drive rather than iron deficiency in pediatric sickle cell disease. Pediatr Blood Cancer. 2010; 55(1):141-144.

8. Al-Saqladi AW, Bin-Gadeem HA, Brabin BJ. Utility of plasma transferrin receptor, ferritin and inflammatory markers in children with sickle cell disease. Paediatr Int Child Health. 2012;32(1):27-34.

9. Hebbel RP. Reconstructing sickle cell disease: a data-based analysis of the "hyperhemolysis paradigm" for pulmonary hypertension from the perspective of evidence-based medicine. Am J Hematol. 2011;86(2):123-154

10. Allen J, Backstrom KR, Cooper JA, et al. Measurement of soluble transferrin receptor in serum of healthy adults. Clin Chem. 1998; 44(1):35-39.

11. Rees DC, Porter JB, Clegg JB, Weatherall DJ. Why are hemoglobin F levels increased in $\mathrm{HbE} /$ beta thalassemia? Blood. 1999;94(9):31993204

12. Brewin JN, Rooks H, Gardner K, et al. Genome wide association study of silent cerebral infarction in sickle cell disease (HbSS and HbSC). Haematologica. 2021;106(6):1770-1773.

13. Rana S, Houston PE, Wang WC, et al. Hydroxyurea and growth in young children with sickle cell disease. Pediatrics. 2014;134(3):465472.

14. Schuchard SB, Lissick JR, Nickel A, et al. Hydroxyurea use in young infants with sickle cell disease. Pediatr Blood Cancer. 2019; 66(7):e27650

15. Park SY, Matte A, Jung Y, et al. Pathologic angiogenesis in the bone marrow of humanized sickle cell mice is reversed by blood transfusion. Blood. 2020;135(23):2071-2084

16. Ballas SK. The Evolving Pharmacotherapeutic Landscape for the Treatment of Sickle Cell Disease. Mediterr J Hematol Infect Dis. 2020;12(1):e2020010.

17. Pule GD, Mowla S, Novitzky N, Wiysonge CS, Wonkam A. A systematic review of known mechanisms of hydroxyurea-induced fetal hemoglobin for treatment of sickle cell disease. Expert Rev Hematol. 2015;8(5):669-679. 